\title{
Entre a escola e o abrigo: estigmas, conflitos e insucesso escolar de adolescentes
}

\author{
Between school and shelter: stigmas, conflicts and school failure \\ of adolescents
}

\author{
Alcione Januária Teixeira da Silveira ${ }^{1}$ \\ Marlice de Oliveira Nogueira ${ }^{2}$ \\ Luciano Campos da Silva ${ }^{3}$
}

\section{Resumo}

O artigo apresenta resultados de uma pesquisa que investigou a experiência social de adolescentes cujos processos educativos são vivenciados ao mesmo tempo na escola e em uma instituição de acolhimento. O percurso metodológico foi de natureza qualitativa, englobando entrevistas semiestruturadas aplicadas aos adolescentes, seus professores, seus educadores, além de uma pesquisa documental exploratória e de um questionário aplicado à psicóloga da instituição. Os dados foram analisados a partir de um aparato teórico inspirado, principalmente, na noção de experiência social de François Dubet. Os resultados indicam que os

\footnotetext{
${ }^{1}$ Possui graduação em Psicologia pelo Centro Universitário do Leste de Minas Gerais; MESTRADO EM EDUCAÇÃO pela Universidade Federal de Ouro Preto; Especialização em Gestão de Politicas Públicas Gênero e Raça pela Universidade Federal de Viçosa; Especialização em UNIAFRO - Promoção de Igualdade Racial pela Universidade Federal de Ouro Preto e MBA em Gestão de Recursos Humanos e das Relações Trabalhistas pela Faculdade Redentor. Atua como Docente no curso de Psicologia na Faculdade Vértice Univértix e como Psicóloga no Sistema Único de Saúde. Atualmente coordena o Grupo de Estudos GEPP - Grupo de Estudos em Políticas Públicas na Faculdade Univértix. ${ }^{2}$ Possui graduação em Pedagogia pela Universidade de Itaúna (1988), MESTRADO EM EDUCAÇÃO pela Pontifícia Universidade Católica de Minas Gerais (2004) e DOUTORADO EM EDUCAÇÃO pela FAE-UFMG com pesquisa no campo da Sociologia da Educação, intitulada "Pais professores e a escolarização dos filhos" (2011). Atua desde 2004 na docência do ensino superior, com experiência em cursos de Pedagogia e demais licenciaturas, como também em atividades de pesquisa e de extensão universitária. ${ }^{3}$ Graduado em Pedagogia pela Universidade Federal de Minas Gerais ? UFMG (1999). Doutor em Educação pela UFMG (2007), com Estágio Sanduíche na Universidade de Lisboa (Portugal). Professor Associado do Departamento de Educação do Instituto de Ciências Humanas e Sociais da Universidade Federal de Ouro Preto (ICHS-UFOP) e professor permanente do Programa de Pós-Graduação em Educação da UFOP. Atualmente é Diretor do Instituto de Ciências Humanas e Sociais da UFOP (ICHS-UFOP).
}

Interfaces da Educ., Paranaíba, v.11, n.32, p. 432 - 465, 2020 
processos de escolarização e os itinerários escolares dos adolescentes institucionalizados sob a tutela do Estado, além de uma clivagem imposta pela origem social e cultural, são influenciados pelas condições sociais e educacionais vivenciadas por eles em uma dupla e híbrida experiência social permeada por tensões e situações de fuga física e simbólica, estigmas, isolamento, problemas no aprendizado escolar, dificuldades de inclusão nas turmas e na escola, conformação e negação do sujeito, tanto no acolhimento institucional quanto nas vivências escolares.

Palavras-chave: Experiência Social. Adolescente Institucionalizado. Professor. Educadores.

\begin{abstract}
The article presents results of research that investigated the social experience of adolescents whose education is experienced both at school and in an institutionalized shelter. The methodology was of a qualitative nature, encompassing semi-structured interviews applied to adolescents, their teachers, their educators, in addition to an exploratory documentary research and a questionnaire completed by the institution's psychologist. The data were analyzed using a theoretical framework inspired mainly by François Dubet's notion of social experience. The results indicate that the schooling processes and school pathways of institutionalized adolescents under the tutelage of the State, in addition to a division imposed by social and cultural origin, are influenced by the social and educational conditions experienced by them in a double and hybrid social experience permeated byo tensions and situations of physical and symbolic escape, stigmas, isolation, problems in school learning, difficulties in inclusion in classes and at school, subject formation and denial, both in institutional care and in school experiences.
\end{abstract}

Keywords: Social Experience. Institutionalized Adolescent. Teachers. Educator. 


\section{Introdução}

No Brasil, um Cadastro Nacional de Adoção foi instituído por meio da Resolução $N^{\circ} 54$ do Conselho Nacional de Justiça (CNJ), em 29 de abril de 2008, que foi modificada pela Resolução CNJ No 93 de 27/10/2009 e, mais recentemente, pela Resolução CNJ N.289, de 14/08/2019 que dispôs sobre a implantação e funcionamento do Sistema Nacional de Adoção e Acolhimento (SNA). Contudo, como nos lembra Rizzini (2003), embora tenhamos, recentemente, por meio do SNA, informações oficiais sobre o acolhimento no Brasil, os dados históricos mostram que são várias as gerações de crianças e adolescentes que passaram parte de suas vidas abrigadas em instituições de acolhimento em nosso país.

Segundo informações publicadas pelo Conselho Nacional de Justiça (CNJ) em 2019, existiriam atualmente no Brasil um número estimado de 47 mil crianças vivendo em instituições de acolhimento, sendo que, deste total, 42 mil são pretendentes habilitados em um cadastro nacional para adoção (CONSELHO NACIONAL DE JUSTIÇA, 2019).

Conforme descrevem as orientações técnicas do Serviço de Acolhimento para Criança e Adolescente (BRASIL, 2009), os serviços de acolhimento destinam-se a abrigar e acolher crianças e adolescentes em medidas protetivas por determinação judicial, em decorrência de séria violação de direitos desses sujeitos. Dentre os motivos mais frequentes para as crianças e os adolescentes estarem em instituições de acolhimento destacam-se, segundo os dados do documento "Um Olhar Mais Atento aos Serviços de Acolhimento de Crianças e Adolescentes no País” (BRASIL, 2013), a negligência dos pais ou responsáveis no tocante aos cuidados e proteção aos filhos e a dependência química por parte dos pais ou responsáveis. Esses dois principais motivos são seguidos por outros como o abandono, a violência doméstica e a violência sexual. 
Embora, a institucionalização de crianças e adolescentes em abrigos constitua uma realidade bastante presente no Brasil, o universo das instituições de acolhimento (e também a realidade vivenciada neles por crianças, adolescentes e educadores) ainda é pouco explorado nas pesquisas em educação principalmente quando a temática central é a relação entre a vivência da institucionalização e a escolarização das crianças e dos adolescentes acolhidos (CRUZ, 2004 e TAVARES, 2014, por ex.). Trata-se, sem dúvida, de uma realizada bastante "invisibilizada", sobre a qual a sociedade em geral, pesquisadores, educadores e gestores das políticas educacionais ainda pouco conhecem.

Diante desse cenário é que se configura o objeto desta pesquisa que investigou a experiência social de adolescentes em situação de acolhimento institucional, na perspectiva dos próprios adolescentes, de seus educadores e professores. Adolescentes que vivenciam experiências sociais e educativas, imbricadas, ao mesmo tempo, por arranjos e situações familiares adversas e por condições simbólicas e materiais particulares advindas das vivências em locais de acolhimento. Grande parte dos processos formativos desses estudantes ocorre na confluência das experiências que eles constroem quotidianamente na escola e no abrigo. Assim, o objetivo principal da pesquisa foi investigar as experiências sociais de adolescentes que vivenciam seus processos formativos simultaneamente na escola e nos locais de acolhimento. Como hipótese central, partimos da ideia de que os processos de escolarização e os itinerários escolares desses adolescentes institucionalizados sob a tutela do Estado, além de uma clivagem imposta pela origem social e cultural, são influenciados pelas condições sociais e educacionais vivenciadas por eles em uma dupla e híbrida experiência social no acolhimento institucional e nas escolas. De um modo mais específico, buscamos responder às seguintes questões: a) Quais experiências sociais são construídas pelos adolescentes que vivenciam uma situação de formação educativa simultânea na escola e no abrigo? b) De que modo essas experiências estão imbricadas e articuladas pelas interações com seus 
professores e educadores nos contextos da instituição de acolhimento e da escola?

O trabalho se baseou principalmente na noção de experiência social de François Dubet que apareceu como elemento teórico relevante, diante dos dados coletados, especialmente para a análise das experiências de escolarização dos adolescentes pesquisados. Segundo Dubet (1994), não existe uma socialização total, não porque o indivíduo "escape do social", mas porque sua experiência se inscreve em variados registros nem sempre congruentes e, por vezes, contraditórios. Ao mesmo tempo, os indivíduos atuam (nem sempre de modo consciente) sobre as próprias experiências de socialização, modificando-as. Nesta perspectiva, a noção de experiência social pretende construir uma alternativa à polarização entre subjetivismo e objetivismo na construção do individuo, designando as condutas individuais e coletivas dominadas pela heterogeneidade de seus principios constitutivos e pela atividade dos indivíduos que devem construir o sentido das suas práticas no bojo desta heterogeneidade.

Assim, estudar os processos educativos de adolescentes inspirados no conceito de experiência social (DUBET, 1994), implica compreendê-los como imbricados e articulados em múltiplas dimensões e por meio de diversificadas interações. E, também, buscar compreendê-los não apenas produtos diretos do mundo escolar e do mundo no abrigo ou mesmo da negação ou enfrentamento desses dois mundos. As aprendizagens, seja na escola ou no abrigo, são, antes de tudo, experiências sociais e somente podem ser compreendidas quando confrontadas e analisadas em seu contexto social mais amplo, e no caso desse estudo, quando se leva em conta, a imbricação das vivências dos adolescentes na instituição de acolhimento e na escola.

\section{O desenho metodológico da pesquisa}

Para a realização da investigação, foi selecionada uma Unidade de Acolhimento localizada em um municipio interiorano do estado de Minas Interfaces da Educ., Paranaíba, v.11, n.32, p. 432 - 465, 2020 
Gerais, distante a $170 \mathrm{~km}$ da capital. A pesquisa foi desenvolvida por meio da aplicação de entrevistas semiestruturadas, pesquisa documental exploratória, além de um questionário. Compreende-se que a metodologia qualitativa é a mais coerente para a compreensão do objeto estudado. Nas palavras de Ludke (1986), a abordagem qualitativa tem o ambiente "natural" como sua fonte direta de dados e o pesquisador como seu principal instrumento, os dados coletados são predominantemente descritivos, a preocupação com o processo é muito maior do que com o produto, o significado que as pessoas dão às coisas e à sua vida são focos de atenção especial pelo pesquisador e a análise dos dados tende a seguir um processo indutivo.

Entrevistas semiestruturadas foram aplicadas às crianças e adolescentes institucionalizados, seus professores, educadores, totalizando 12 sujeitos participantes da pesquisa. Para a seleção dos sujeitos foram levados em consideração alguns critérios:

a) Crianças e adolescentes: foram selecionadas quatro crianças e/ou adolescentes que estivessem frequentando o ensino fundamental I ou ensino fundamental II, sendo dois do sexo masculino e dois do sexo feminino, e ainda, que tivessem tempo de permanência na instituição acima de um ano. Os critérios de tempo na instituição e etapa de escolarização se justificam tendo em vista o objeto da pesquisa, que articula experiências de escolarização e de institucionalização.

b) Educadores atuantes na unidade de acolhimento campo da pesquisa: todos os quatro profissionais em exercício na unidade foram selecionados, tendo em vista o número restrito de profissionais.

c) Professores: foram entrevistados os docentes que lecionavam para os adolescentes selecionados e que, de preferência, passavam mais tempo com eles, no caso do Ensino Fundamental II (preferencialmente professores de Português e Matemática, disciplinas que normalmente têm uma carga horária semanal maior no currículo escolar).

Além das entrevistas, foi aplicado um questionário à psicóloga responsável pela instituição com a finalidade de coletar dados complementares sobre os 
adolescentes investigados. A aplicação do questionário contribuiu para a obtenção de dados sobre os motivos e período do acolhimento dos adolescentes, assim como as condições socioeconômicas de suas famílias de origem.

\section{Os adolescentes, seus educadores e professores}

Os quatro adolescentes selecionados receberam nomes fictícios: Lara, Mairon, Almir e Maria. Quando foram abrigados estavam sob a responsabilidade das mães, enquanto os pais eram completamente ausentes na vida deles. Os quatro estavam acolhidos na instituição há mais de três anos, sendo que o tempo máximo era o de Maria que estava acolhida há 8 anos e sete meses, prazo superior ao estabelecido pela lei $13.509 / 2017$. A idade dos adolescentes variava de 12 a 16 anos e eles ou elas frequentavam o ensino fundamental II, sendo que todos apresentavam defasagem em seu itinerário escolar e episódios de recuperações, reprovações e abandono escolar.

O motivo para o acolhimento registrado nos documentos da instituição era o abandono em três casos (Lara, Mairon e Maria) e violência doméstica no caso do adolescente Almir. Havia também o registro de situação de drogas, álcool e prostituição nas famílias de origem dos adolescentes, sendo que Lara e Mairon tinham registro de pai desconhecido e o pai de Almir já havia falecido. Os dados sobre os adolescentes reiteram uma realidade ainda persistente no Brasil, de famílias vivendo em situação de extrema vulnerabilidade econômica, social, cultural e psíquica. Ressalta-se que Lara e Maicon são irmãos e foram acolhidos pela instituição na mesma data.

Os educadores que participaram da pesquisa receberam os nomes fictícios de Davi, Milena, Milka e Jamile. Os quatro educadores tinham idade entre 28 e 40 anos e não possuíam formação específica para atuar em instituições de acolhimento. Davi tinha ensino superior completo, Milena ainda estava cursando este nível de ensino e Milka e Jamile possuíam apenas o ensino médio completo. Em relação ao trabalho na instituição, 
todos eram contratados pela prefeitura municipal, sem vínculo permanente e o tempo de atuação no abrigo pesquisado variava de 1 ano e 10 meses a 8 anos.

Os professores entrevistados receberam os nomes fictícios de Tamires, Eduardo, Marlene e Daniela. Eles atuavam nas escolas públicas em que os adolescentes estudavam, em turmas de ensino fundamental II. Os quatro professores eram bastante experientes na profissão: Tamires, com 40 anos de carreira, Eduardo com 21, Marlene com 20, e Daniela com 24 anos de profissão. Todos tinham formação em nível superior, e cursaram a pósgraduação lato sensu, sendo que Maria cursou o Mestrado em Educação. Além disso, Maria e Eduardo fizeram dois cursos de graduação. Dos quatro docentes, três atuavam com extensa carga horária de trabalho (36, 40 e 44 horas semanais), e apenas a docente Tamiris, já aposentada em um cargo público, tinha carga horária inferior, compondo 24 horas semanais.

\section{A relação com a escola e com os professores}

As experiências sociais dos adolescentes pesquisados não eram influenciadas apenas pelas suas vivências nas famílias e na instituição de acolhimento, mas eram atravessadas e mediadas também pela relação com a escola e com os professores.

Nas informações obtidas por meio do questionário respondido pela psicóloga do abrigo, contatamos que todos os adolescentes estudavam em escolas públicas no município: Lara, Mairon e Almir estavam matriculados na rede municipal e Maria na rede estadual.

Os adolescentes acolhidos iam para escola acompanhados dos colaboradores da instituição e de um motorista. A educadora Milka informou que, na realidade das escolas em que os adolescentes eram matriculados, o mais comum era que os outros estudantes fossem para a escola sozinhos e a pé. Apenas em pouquíssimos casos os pais levavam os filhos de moto, especialmente quando o início das aulas coincidia com o horário de trabalho de algum familiar. No entanto, segundo a educadora, as crianças e adolescentes do abrigo eram sempre transportados para a escola no carro 
oficial da instituição. Maria era a única adolescente que se deslocava sozinha e a pé para a escola, segundo ela "porque eu já sei me virar na rua".

Sobre essa possivel autonomia da adolescente Maria, a educadora Jamile relata que, aos poucos, os profissionais do abrigo tentavam construir a autonomia dos adolescentes para que eles pudessem resolver as coisas e saírem sozinhos pelas ruas. Ela afirma ainda que os profissionais acompanhavam esse processo ligando para os locais para se certificarem de que os adolescentes estavam seguros e agindo de forma "correta". Assim, segundo a educadora, nos casos em que os adolescentes começavam a mentir e se desviar do caminho, os profissionais passavam a acompanhá-los. Os educadores explicaram também que levavam os adolescentes caminhando para a escola, quando a distância era curta e de ônibus ou no carro oficial quando a escola se situava mais distante do abrigo. A educadora destacou também que o carro utilizado tinha a logomarca da assistência social e que os adolescentes detestavam isso, que ficavam constrangidos, pois todos saberiam que moravam no abrigo, e que, em um caso específico, a adolescente tinha tanta vergonha que não aceitava andar no carro. Almir, por exemplo, apesar de relatar um sentimento de tranquilidade para se deslocar no carro da instituição, denotava certo constrangimento ao afirmar que o colega "vê e mexe", chamando-o de "ô casa lar1". Ele ainda afirma que reagia a esses insultos e retrucava dizendo: "sou casa lar com muito orgulho".

Os educadores relataram que mediante os xingamentos de colegas, os adolescentes reagiam com palavras de calão, e que, embora as agressões fossem cotidianas, elas não estavam "naturalizadas" para os adolescentes, que se sentiam extremamente desconfortáveis e constrangidos com a situação e com o estigma por ela gerado.

Em relação aos professores entrevistados, apenas dois mencionaram o assunto. O professor Eduardo relatou que questionou a direção da escola

\footnotetext{
1 Anteriormente, o serviço de acolhimento no município era chamado de Casa Lar, no entanto, passou por uma reorganização do serviço e agora pertence à modalidade de Abrigo Institucional. No entanto, a antiga denominação continua sendo largamente utilizada pelos moradores da cidade.
}

Interfaces da Educ., Paranaíba, v.11, n.32, p. 432 - 465, 2020 
sobre o porquê de o aluno Mairon chegar à escola no carro da assistência social, mas que nunca vivenciou nenhum preconceito e enfatizou que na escola todos lidavam com essa situação com naturalidade. Já a professora Tamiris mencionou ouvir os alunos chamarem uma das adolescentes de "casa lar", no entanto, ela entendia a situação como "brincadeira de menino". Percebe-se nos relatos que os professores tendem a "naturalizar" o preconceito e o estigma, percebendo-o como "brincadeira" e "zuação".

Esses adolescentes estão sujeitos a uma forte estigmatizacão e a todo um conjunto de estereótipos negativos ligados ao processo de institucionalização. E esse estigma (o menino casa-lar) produz uma relação com o outro despersonalizada, impessoal, em que a individualidade do sujeito é apagada, embaçada, e ressurge como um produto das características comuns típicas do estigma construído (DUBET, 1994). Assim, o estigma constrói uma categoria de marcas internas que ao serem externalizadas compõem uma visão totalizante do sujeito (o da casa-lar). Desse modo, os dados indicam que a atitude mais comum entre os adolescentes pesquisados consistia em aparentemente desprezar o estigma e, mostrar-se aos outros por meio de violência e/ou de comportamentos de negação, assumindo para si mesmo, o personagem do estigma ("ah...sou da casa lar mesmo").

Os signos são, portanto, informações sociais (GOFFMANN, 1982), assim como o carro e sua marca institucional que transmitem a informação contra a vontade do sujeito que o utiliza, convertendo-se em um estigma que posiciona e condiciona (ao menos em parte) o indivíduo à sua situação social. Ainda, devemos considerar a construção desse estigma como sendo responsável pelo fortalecimento dos processos de exclusão, o que potencializa as desigualdades. Existe uma hierarquia social, problemas sociais que definem a distância social, a identidade e a integração, ou seja, uma certa adaptação à condição de vida (integração essa advinda dos acúmulos de várias desvantagens como por exemplo, pobreza, isolamento e má reputação), que coloca o indivíduo numa posição frágil, de excluído, 
dominado, estigmatizado, na qual os adolescentes dependem fortemente da opinião do outro para a construção de si (DUBET, 1994).

Segundo as Orientações Técnicas do Serviço de Acolhimento para Crianças e Adolescentes, os acolhimentos não devem instalar placas indicativas na instituição, evitando nomenclaturas que remetam a aspectos negativos para assim não estigmatizar os acolhidos (BRASIL, 2009). Como pudemos constatar em relação ao veículo, nem sempre essas regulações são levadas em conta pelas instituições e pelo poder público, negligência que fortalece a situação de exclusão social. Muito além do carro enquanto um objeto social, estão as marcas, as situações e as condições existenciais em que esses adolescentes estão expostos. Com isso, convivendo diariamente com a produção e reprodução desses estigmas, os adolescentes passam a ser transvestidos de uma marca, um sinal de alerta, de ausência de produtividade, criatividade ou deformações éticas e morais, perdendo em parte sua individualidade diante do outro e de si mesmo, e configurando-se como o menino ou a menina "casa lar".

Goffman (1982), apresenta o estigma como um atributo capaz de produzir um descrédito na vida da pessoa, que o coloca como uma marca ou desvantagem em relação ao outro. Para os estigmatizados, a sociedade reduz suas oportunidades e seus esforços, impõe a perda da identidade social, o descreve como diferente que passa a ser nocivo e incapaz, não dando conta de responder os parâmetros da sociedade. Dubet (1994), interpreta essas experiências vividas pelos indivíduos como uma ameaça e destruição da personalidade, fazendo com que eles vivam "sacudidos", levados pelas circunstâncias e efeitos do grupo que impedem, ou ao menos, dificultam que eles se vejam e se compreendam como autores da própria vida.

\section{Almir e a experiência da negação}

Os educadores e os próprios adolescentes expressam diversos sentimentos relativos ao estigma a que estão submetidos pelo fato de estarem institucionalizados. Almir, por exemplo, relatou desenvolver 
comportamentos de resistência e reação aos processos estigmatizadores e excludentes que vivencia cotidianamente na escola e fora dela. Faz isso revidando, contestando, transgredindo, e, assim, por meio dos modos possiveis de reação ao controle e ao estigma, foi construindo (nem sempre de modo consciente) sua própria experiência social: "os meninos são ruim porque mexem comigo de apelidos, mas aí eu coloco apelidos e mexo com eles também".

Poderíamos pensar que a experiência de Almir evidencia uma espécie de plano de ação a empreender diante do estigma que possui (GOFFMANN, 1982)? Os resultados parecem indicar que sim, mas poderíamos acrescentar que são "planos de ação possiveis", construídos de modo inconsciente, na maioria das vezes, e no escopo da vulnerabilidade das condições de existência deste adolescente. Ainda que diante desta vulnerabilidade e do forte controle social, as subjetividades do adolescente não se apagavam, pois elas se mostravam presentes: "eu mexo com eles também".

Contudo, os educadores relataram considerar que os adolescentes institucionalizados apresentam certa desvantagem em relação aos seus colegas no que tange à vivência na escola e ao processo de escolarização. Relataram que para eles a escola não estaria em primeiro lugar em suas vidas e que eles estariam emocionalmente "sofridos". Almir, assim como os outros três adolescentes, vivenciaram itinerários educacionais interrompidos e com marcas profundas do fracasso escolar. As análises feitas por Goffman (1982), nos permite mais uma vez questionar o que pode ser dito sobre a identidade social de uma pessoa que, em sua rotina diária, vivencia uma apresentação compulsória em público e é exposta aos estigmas e marcas sociais. Certamente, os processos de exclusão vivenciados por esses adolescentes em seu percurso escolar (rupturas, recuperações, reprovações) são potencializados pelo estigma que vivenciam nos diversos espaços sociais e, principalmente, na escola.

Com isso, vemos a sinceridade ambígua de Almir ao dizer que "até gosta da escola", mas não gosta de "ficar na escola", que não "gosta de estudar", relatando que vai à escola todos os dias, mas que "pega sua mochila e vai 
embora quando quer". Almir relatou que o comportamento dele na escola é diferente todos os dias, que quer brincar, conversar, ir embora, mas que tem boa convivência com todos lá. Sobre o aprendizado, destacou como errado o fato dele aprender "palavrão e desrespeito", mas que usa esses "aprendizados" para as "coisas certas", como por exemplo, para se defender das agressões e do preconceito. Almir explicou que aprende, tanto na escola quanto no abrigo, a estudar e ter "educação".

Os educadores relataram que Almir tinha muitos problemas de indisciplina, problemas com o cumprimento de regras, que ele não gostava de ficar na sala de aula e que perturbava os colegas. Os professores confirmaram este comportamento do adolescente, afirmando que ele era muito inquieto, que "agitava todo mundo na escola". Contudo, o adolescente também foi descrito por eles como muito inteligente e que não apresentava dificuldade para aprender, e sim, com a formalização da escrita. Os professores atribuem essa dificuldade com o código escrito ao fato de Almir não permanecer na sala de aula. A educadora Milena relatou que "parece que ele quer descobrir tudo de uma vez". Já a educadora Jamile enfatizou que Almir "é uma interrogação na nossa vida". Na perspectiva dos educadores e dos professores, Almir é um adolescente inteligente ("dá conta de estudar"), mas os profissionais não conseguiriam encontrar estratégias para fazer com que ele se empenhasse nessa tarefa. Eles também afirmaram que a escola "não está mais aguentando o adolescente" e que ele ficaria muito tempo fora da sala de aula e ausente na escola. Daniela, professora de Almir ressalta também que a escola permitiria essa evasão do aluno e não desenvolveria nenhuma estratégia ou controle sobre as suas saídas. Ao contrário, a escola deixava o portão aberto, sendo que ele deveria ficar fechado durante o período das aulas. Daniela afirmou também que não entendia o motivo do comportamento do adolescente, uma vez que, na sua percepção, todos na escola o tratavam bem.

Ainda sobre as experiências escolares de Almir, o professor Eduardo relata que embora não lecione para o adolescente, já encontrou com ele nas aulas de reforço escolar. Ele relata que, naquelas ocasiões, o adolescente não Interfaces da Educ., Paranaíba, v.11, n.32, p. 432 - 465, 2020 
apresentou problemas de comportamento e atribui isso a uma postura mais exigente e firme diante do aluno, além do uso de uma linguagem mais próxima à realidade do estudante. Ele relatou: "xinguei e falei com ele: aqui você vai ficar do meu jeito, não tem seu jeito aqui não, ah menino oh!”.

Por outro lado, na visão da educadora Jamile, a escola não conseguiria garantir a segurança do aluno fora do espaço escolar, por isso não deveria permitir as suas saídas e ausências. Além dessa experiência, a educadora Jamile questionou o papel da escola e das posições dos profissionais na escola mediante as dificuldades encontradas por Almir na realização das atividades escolares.

Ah lá! Está trazendo de novo! Num falei que traziam, quem ninguém está querendo esse menino em casa. Mas não sabendo ela, que ele está no horário de escola, então ele tinha que tá na escola, ela que tá mal informada. Hoje tinha um senhor lá que, eu não sei o nome dele, eu vou até me informar, procurar saber o nome dele, ele falou assim: Ah lá! Já tá trazendo, nem elas tá aguentando o menino em casa. Mas num é! Ele está no horário de escola, então ele tem que estar na escola, aí ele me pede pra trancar ele no quarto. Tranca ele no quarto! Deixa ele três, quatro dias sem comer! Eu ainda não tive uma resposta pra dar pra ele, mas eu vou elaborar uma. (Educadora Jamile).

Como se vê, escola e abrigo parecem estar em dois polos, de um lado a escola culpabiliza o abrigo pelos maus comportamentos dos adolescentes e o abrigo, por sua vez, responsabiliza a escola pela dificuldade em lidar com tais comportamentos. De acordo com Dubet (1994), podemos pensar que algumas ações das duas instituições reforçam as desigualdades sociais, assim como geram suas próprias desigualdades nos processos de escolarização. Assim, os comportamentos de indisciplina de Almir, arredios ao mundo escolar e às suas regras, produziam conflitos com os diferentes profissionais da escola que, por sua vez, se refletiam em um maior distanciamento, e no fracasso escolar do adolescente.

Quando Almir foi questionado sobre as dificuldades encontradas por ele na escola, o adolescente relatou que recorre a "fessora" e disse que ela resolve os problemas conversando com ele. Mas, parece que o histórico de conflitos de Almir se repete na instituição e na escola, tanto que a professora descreve muitas dificuldades para lidar com ele. 
Ressalta-se que, para Dubet (1994), a sociabilidade está longe de ser sempre amiga e cordial. Para esse indivíduo ameaçado, o encontro implica a rejeição. Assim, a maior parte das desordens de Almir com os adultos e professores poderiam ser pensadas como reflexos da complexa experiência social de exclusão e vulnerabilidade que o coloca quase sempre, na posição de se defender ou sobreviver, o que por sua vez, gera mais conflitos, afastamento e exclusão.

Contudo, Almir relata que não vê problema na escola e se culpabiliza pela sua situação, dizendo: “o problema está em mim”. De acordo com Silva (1997), o indivíduo institucionalizado tem capacidade de resistência para defender e preservar valores adquiridos como questão de sobrevivência. Seguindo esse raciocínio, Almir, fortemente tensionado pelos conflitos com a escola e com os professores estaria usando o silêncio como uma forma de hipocrisia, de desdém ao mundo escolar, mas que na verdade se constituía como uma forma de resistência e/ou negação. Ao mesmo tempo, o adolescente ia construindo uma imagem e um pensamento sobre si mesmo, que se confundia entre a adesão e a resistência, e embaçava a sua identidade social, fazendo com que ele se culpabilizasse por viver tal experiência, assumindo uma identidade estigmatizada.

\section{Mairon e as estratégias de "sobrevivência" escolar e social}

Os dados mostram que existe um consenso entre os professores entrevistados sobre o fato de que a escola teria muita dificuldade para lidar com adolescentes, o que acabaria produzindo conflitos com os professores e entre os próprios adolescentes.

Não por acaso, na perspectiva dos professores, o adolescente Mairon também apresentava comportamentos de indisciplina na escola. Para o professor Eduardo, “o adolescente está em uma fase dificil, a adolescência, e ainda mais na condição dele, pois sente falta de alguém para conversar, um pai, uma mãe". Em função disso, o professor relata conseguir entender e relevar os comportamentos inadequados de Mairon: "não vou levar a ferro e 
fogo não", "ele é muito novo para viver tudo que está vivendo", "Mairon tem muitos conflitos, que às vezes está muito bem, às vezes apresenta uns rompantes, que a maior preocupação com ele no momento é em relação às drogas".

Por outro lado, na perspectiva do próprio adolescente, ele teria um bom comportamento na escola, justificando que fazia bagunça, mas que a "bagunça" se dava apenas com os colegas e que, na maioria das vezes, os professores não ficavam sabendo. Ele também explicou que ameaçava os colegas para não contarem sobre os seus atos de transgressão aos professores.

Para os educadores, o adolescente Mairon seria tranquilo e não gostava de ser chamado à atenção. Por esse motivo, sempre tentava manter certo equilíbrio nas relações e em seus comportamentos. Relataram que Mairon era muito inteligente e organizado, mas preguiçoso com as atividades da escola. Na perspectiva dos educadores, Mairon não gostava de frequentar a escola porque tinha dificuldades com os conteúdos escolares, mas como o adolescente era muito esperto e "estrategista", sempre conseguiria disfarçar essas dificuldades.

Durante toda a entrevista Mairon procurou demonstrar que tinha resistência e desagrado com os assuntos escolares e, quando questionado sobre a participação dos responsáveis da instituição de acolhimento na escola, disse: "uai, mas eu não sei não, num sou diretor da escola não". Enfatizou também que "não aprendia nada na escola" e que "tudo relacionado à escola é ruim", que mediante alguma dificuldade na escola não procurava ninguém, resolvia sozinho, que não gostava dos professores e que "eles nem sabe dá aula". Assim, Mairon parecia sempre dividido, cindido pela necessidade de adaptação à escola e ao mundo social e a uma busca identitária que o "livrasse" da situação de excluído e estigmatizado.

No entanto, não queremos generalizar a desordem e a violência na escola como formas de revolta contra a exclusão, como se essa fosse o único mecanismo explicação desses fenômenos. Sabemos que a indisciplina e a violência são fenômenos bem mais complexos cuja explicação passa por 
exemplo por fatores como a inexistência de uma socialização familiar adequada, o sentido conferido pelo estudante à escola, aspectos da gestão escolar e da gestão de sala de aula, entre outros. Por vezes, a conformação e a submissão também se constituem como mecanismos ou estratégias, nem sempre conscientes, de resistência ou sobrevivência social e psíquica.

\section{Maria e Lara: entre a conformação e o conflito}

Em seus relatos, os educadores demonstraram um sentimento ambíguo em relação aos adolescentes, que se situa em dois extremos: por um lado, expressaram laços afetivos com os adolescentes e um empenho em thes oferecer segurança e cuidado e, por ouro, um desalento e um sentimento de impotência diante da vulnerabilidade social a qual estavam submetidos.

Eles se questionavam sobre a possibilidade de ajudar os adolescentes, mas consideravam que só o fato de estarem institucionalizados já os tornavam "fracos" diante do mundo e, principalmente, da escola. Uma educadora relata que Maria, por exemplo, tinha muitas fragilidades e apresentava dificuldades para resolver seus problemas, estando em grande defasagem escolar. A educadora relatou que em um dado momento Maria foi a uma loja fazer uma compra e não conseguiu avaliar se o dinheiro que tinha disponivel era suficiente para comprar o objeto de seu desejo.

Ainda sobre Maria, os educadores a descreveram como uma adolescente "estressada", cujo comportamento oscilava muito. Disseram que quando era interpelada pelos educadores sobre algum tipo de comportamento, a adolescente respondia de forma mal-educada e tinha dificuldades em cumprir as regras do abrigo e da escola. Também afirmaram algumas qualidades, como o capricho e a organização. Destacaram o fato de que Maria ficou grávida aos 15 anos e de que, desde então, não estava frequentado a escola, se dedicando aos cuidados com o bebê, que também se encontra institucionalizado. O educador Davi considerou que "a escola não 
está preparada para receber Maria e os conflitos que ela vivencia hoje, então ela não dá conta de ficar naquele lugar".

A professora Marlene relatou que nos primeiros anos em que lecionou aulas para Maria ela respondia inadequadamente a todo mundo, brigava com todos os professores, mas que depois mudou de comportamento ficando mais tranquila. Relatou que a adolescente não apresentava dificuldade cognitiva, mas sim dificuldades de sociabilidade com os colegas da sala, mantendo-se, na maioria das vezes, inquieta e reclusa durante as aulas.

Já Lara era vista pelos professores e pelos educadores como uma adolescente mais "dócil” em relação ao mundo escolar. Segundo eles, mesmo apresentando profundas dificuldades de aprendizagem, se "conformava" a esse mundo. A própria adolescente relatou que gostava da escola, mas que às vezes conversava durante as aulas e a professora mandava bilhete para os profissionais do abrigo reclamando de suas atitudes. A educadora Jamile relatou que Lara sempre teve de enfrentar problemas na escola, além da grande defasagem escolar ela era muito grande para a sua idade e sempre se destacava entre os colegas.

Os educadores também destacaram que Lara era afetada não somente pelas suas dificuldades de aprendizagem, mas também pelas múltiplas e profundas desigualdades oriundas, por exemplo, do racismo e de preconceitos relacionados a sua aparência física.

Lara para mim é uma criança! Ainda ela... É a que foi mais lesada em todos os sentidos porque... Porque ela é negra, porque é obesa, porque é o tempo todo, ela é rotulada como feia, como diferente, estranha, fedorenta, e isso tudo influencia na aprendizagem. Ela vai para escola com tudo isso na cabeça, e aí ela entende que ela não é capaz, que ela não é... ela tem um problema muito sério com autoestima e a gente o tempo todo tava tentando trabalhar isso com ela e... o que as pessoas não conseguem entender, é que a criança ou adolescente na escola, ela é o que ela é na vida dela. (Educador Davi).

Para Dubet (1994), o racismo é algo onipresente e não é somente um discurso, é violência e agressão de fato que se manifesta na segregação que proíbe os sujeitos de acessar certos empregos, certos bairros, certas escolas e etc. O racismo é sutil quando se apresenta através de olhares e atitudes 
que invadem a existência e negam o indivíduo como pessoa e passam a reduzi-lo a seu grupo. O racismo afeta fortemente a experiência social do adolescente, o racismo tem efeito cognitivo e transforma a experiência social (DUBET, 1994, p.205).

Lara relatou sobre as suas dificuldades escolares, mencionando as aulas de Educação Física. A adolescente afirmou que "fazer esse trem de ginástica que o professor dá, é porque tem coisas que ele manda fazer, só que eu não consigo aprender rápido". No entanto, afirmou que explica para o professor essas dificuldades e que ele sempre a ajuda. Relatou sobre o aprendizado na escola e disse que a frequência à escola faz com que ela possa aprender a estudar, a fazer as atividades, as obrigações, as tarefas e "não brigar" com os colegas. A adolescente afirmou também que a convivência na escola também fazia com que ela aprendesse "coisas erradas", como "mexer com os outros e ficar com brincadeiras de mau gosto".

Assim, embora Maria e Lara fossem vistas pelos educadores e professores como adolescentes mais "fáceis de lidar" em oposição dois aos meninos Almir e Mairon, parece que elas vivenciavam em lados opostos, tanto a experiência da institucionalização quanto da escolarização. Enquanto Maria, tensionada pela sua história de vida e pelas condições impostas pela maternidade precoce, oscilava entre o conflito (agressões verbais aos professores e colegas e infrequência) e a adesão ao mundo escolar (capricho e organização, cumprimento de tarefas escolares), Lara, retraída, tímida e fortemente afetada pelo racismo estrutural, conformava-se à escola e ao abrigo, garantindo assim, a sua sobrevivência social.

\section{Para que serve a escola? Expectativas de futuro}

Por meio das entrevistas, procuramos compreender o sentido da escola para os adolescentes e as expectativas que eles tinham em relação à escolarização. Em todos os casos, eles falaram de um sentimento positivo em relação à escola, embora essa positividade fosse, às vezes, contraditória ou 
confusa em seus relatos. Parecia que eles apresentavam um discurso genérico de que a escola é algo bom, ou seja, os adolescentes pareciam reproduzir um discurso social de que a escola é necessária para a mobilidade social, de que a inserção nela é compulsória e inevitável, mesmo em um cenário social de profundas desigualdades sociais e escolares.

Maicon, ao explicar por que considerava a escola boa, afirmou: "Num sei não, eles falam uai”. No entanto, Maicon relata não acreditar que a escola poderá ajudá-lo em seu futuro. Já os adolescentes Maria, Lara e Almir relataram ser a escola importante para a vida e para o futuro. Maria lembrou, ainda, que não irá deixar seu filho abandonar a escola como ela fez: "É bom ter os estudos, né! A gente tem que ter estudo pra conseguir as coisas". Para ela esse futuro estaria diretamente associado à melhoria de condições sociais básicas como ter um emprego e uma casa.

Mas a escolarização de fato poderia garantir a todos o futuro esperado? No decorrer das entrevistas, foi possivel perceber de forma clara como os adolescentes sofriam pela condição de institucionalização imposta a eles e como a escola não se apresentava como uma possibilidade de escapar a essa situação por não oferecer oportunidades iguais a todos.

Os adolescentes foram questionados também sobre até qual idade imaginavam que iriam estudar. Almir e Lara responderam 15 anos como idade limite. Maria pretendia estudar até se formar no ensino médio e Mairon demonstrou certa submissão ao destino, relatando: "o que Deus me der, tá isso mesmo".

Poderíamos pensar aqui que a alienação do sujeito surgiria como uma falta de sentido? Dubet (1994), nessa perspectiva, descreve uma experiência alienada, um sentimento de viver uma vida sem sentido, de impotência, sentimento de ser espectador da sua própria vida, da experiência de uma privação da autonomia dominada pelo sistema. Talvez isso se justificaria também pela existência de baixas expectativas frente aos estudos, uma vez que, segundo Dubet (1994), podemos falar de um sistema escolar caracterizado por uma forte seleção social, sendo a escola um mundo que distribui de modo muito desigual as oportunidades. 
Logo quando perguntamos aos adolescentes sobre o que eles pretendiam fazer no futuro, Almir fez referência à profissões que exigem um certo grau de escolarização. Quando confrontado com seus relatos anteriores sobre não gostar de estudar e não ficar na escola, ele se esquivou e disse: "então vou trabalhar, eu já tenho carteira de trabalho".

Almir se confunde sobre o seu futuro, mas por outro lado calcula, mesmo que não totalmente de modo consciente, as suas chances reais. Segundo Bourdieu (2013), as expectativas de futuro estão atravessadas e condicionadas (em graus diferentes, dependendo da posição ocupada no espaço social) pelas condições materiais e culturais de vida. Sendo assim, os sujeitos vindos de familias culturalmente e economicamente desfavorecidas fazem um cálculo mais ou menos consciente das suas chances reais de sucesso, tendo em vista as trajetórias sociais de seus pares do grupo social, e, assim, rebaixam suas expectativas para um futuro possivel. O autor descreve ainda sobre aqueles que a escola rejeita, ficando assim, os próprios sujeitos convencidos de que eram eles que não queriam ou almejavam a escola, contribuindo para a persuasão de que eles não foram feitos para a escola e nem para a posição social que poderiam alcançar por meio da escolarização.

Esse fatalismo do destino, previsto por Almir para o seu futuro, também aparece nos discursos dos educadores:

\footnotetext{
Igual, já o Almir. O Almir a gente não vê ele, a gente olha pra ele assim, a gente não vê perspectiva nenhuma. Eu não consigo ver, isso dói, dói porque às vezes a gente fala isso com ele. As vezes a gente fala de uma maneira errada, de uma maneira que não era pra falar, a gente fala, os colegas ouvem: Ele vai virar um mendigo, que ele não gosta de banho. E ele tem pavor, a gente vai na praça, ele morre de medo de ver esse rapaz que fica dormindo na praça, mendigo, ele morre de medo. E quando a coisa tá pegando, tá feia, a gente fala mesmo: Quer ficar igual fulano, Almir? No meio da rua? Então acho que a maneira às vezes que a gente aborda é muito cruel. Não que eu, eu profetizo isso pra ele, que eu quero isso pra ele, jamais... (Educadora Jamile).
}

Já na ótica da professora do adolescente, ele precisava de medicação para melhorar a concentração e assim obter melhor desempenho na escola. Por outro lado, se preocupava com as agressões verbais de Almir e dizia que os docentes tinham medo de que ele praticasse violência física contra eles. Interfaces da Educ., Paranaíba, v.11, n.32, p. 432 - 465, 2020 
As expectativas da professora sobre o adolescente estão marcadas (e rebaixadas) pelas condições vulneráveis em que ele vive, ou seja, as marcas sociais imprimem o futuro no adolescente, como vemos no relato abaixo:

Olha! Se for continuar nesse patamar aí, eu acho que vai chegar um ponto que ele não vai, que vai desistir mesmo, ele não vai querer ir, né? E a gente assim, é complicado falar o destino dele, né? Pode ser que no meio do caminho ele siga um outro caminho, talvez consiga uma profissão...A gente não sabe o que, que pode acontecer né? (Professora Daniela).

De modo similar a Almir, diante de sua situação de vida, e movida pela urgência da necessidade (BOURDIEU, 2008), Maria relata que "agora tem um filho" e o que mais deseja "é sair do abrigo com ele" e não reproduzir o abandono materno que sofreu em sua infância. Ela afirma que não pretende contar ao filho que ele nasceu e morou em um abrigo, desejando protegê-lo do estigma da institucionalização por ela vivido. Relatou ainda que não pensa em nenhuma profissão para o futuro.

Essa ausência de uma expectativa clara para o futuro, também aparece no discurso de Milka, professora de Maria. Na ótica desta docente, os adolescentes institucionalizados têm um destino selado, ou seja, provavelmente teriam comportamentos inadequados e dificuldades na escola. Para a professora, esses adolescentes, incluindo Maria, não conseguiam ter continuidade nas suas atividades e não perceberiam que o abrigo poderia ser bom para eles, protegendo-os de uma situação de muita vulnerabilidade. A professora Marlene também apresenta baixas expectativas escolares para Maria e seus colegas institucionalizados, relatando que, na sua opinião, eles teriam uma carreira escolar curta e uma rápida inserção no trabalho. Marlene acrescenta ainda: "a gente prega esse negócio de que escola é feita pra todo mundo, não é não, não é não, entendeu?”. Como afirma Bourdieu (2007), as expectativas sociais, incluindo as escolares, são moduladas pelas condições de existência simbólica e material dos atores e das famílias. Sendo assim, a experiência material e simbólica da vulnerabilidade à qual os adolescentes pesquisados foram submetidos ao longo da infância e adolescência condicionava (não totalmente e, e nem 
conscientemente) a ação pedagógica e as expectativas da família, da escola ou do abrigo sobre eles.

A adolescente Lara também expressa angústia em relação a um futuro incerto: "É... eu fico pensando quando sair daqui e não ter lugar pra morar... Quando eu fizer 18 anos". Para os educadores, Lara se apresentava como uma adolescente de bom comportamento e, na perspectiva deles, o seu futuro parecia mais promissor. Durante o período das entrevistas, Lara teve guarda provisória entregue a uma família e até aquele momento tudo estava transcorrendo bem. Vale ressaltar, também, a expectativa de sua professora:

Bom... Geralmente, as crianças com grande dificuldade em aprendizagem acabam parando de estudar no $7^{\circ}$ ano ou $8^{\circ}$ ano. No caso de Lara, com ajuda em casa e na escola, acredito que ela consiga fazer o ensino médio. $\mathrm{E}$ quem sabe, após um amadurecimento e um novo olhar, ela não cursa uma faculdade? Depende de como será guiada. (Professora Tamiris).

Contudo, o irmão de Lara, Mairon, se mostrou arredio nas entrevistas, reclamando das perguntas e disse que achou que iriamos falar de outras coisas e não sobre a vida dele. Desse modo, não se manifestou sobre o seu futuro. $\mathrm{O}$ adolescente Mairon permaneceu totalmente fechado quando tratamos sobre o futuro, construindo uma sociabilidade estreita e fugaz, não existindo outro sentido a esta vida social que não seja proteger-se na solidão ou de passar o tempo (DUBET, 1994). Na visão das educadoras Jamile e Milka, o adolescente Mairon vive um conflito interno, que oscila entre "seguir o caminho do bem" (ser um homem trabalhador) e "o caminho do mal" (drogas e tráfico). Elas dizem temer pelo seu futuro. Durante as entrevistas, foi possivel perceber uma certa retração de Mairon, um isolamento de si mesmo, que ocorre em uma complexa situação que oscila entre conflitos, adesão e isolamento. Dubet (1994) descreve que a sociabilidade da retratação resulta da combinação da lógica da integração enfraquecida e de uma exclusão social, logo a exclusão associada à integração comunitária fraca se transformará em consciência infeliz e o indivíduo será responsável pelo seu insucesso.

De modo diferente, o professor Eduardo apresenta expectativas de futuro mais positivas em relação aos adolescentes, quando comparadas às Interfaces da Educ., Paranaíba, v.11, n.32, p. 432 - 465, 2020 
de seus colegas educadores, principalmente, no tocante ao adolescente Mairon:

\begin{abstract}
Eu acredito nele! Eu acredito nele porque é muito inteligente e ele tá fazendo curso, estava até conversando negócio de curso lá agora, e ele: Não! Eu estou fazendo curso. Eu falei: ô Mairon, faz mesmo que depois quem sabe você num consegue fazer outros, né? Você tem que fazer seus cursos mesmo, você tem que tá com ensino médio, porque na hora que terminar, com 18 anos você vai ter que procurar o mercado de trabalho, você vai ter que bater na porta, aí vão te perguntar: Quantos cursos você tem? Quais? Não é quais, é quais e quantos que você tem né? Então só o ensino médio você não vai resolver nada, você tem que fazer curso mesmo. (Professor Eduardo).
\end{abstract}

Os educadores, ao relatar as suas expectativas sobre o futuro dos adolescentes, demonstraram uma forte preocupação devido à consciência das marcas deixadas nos adolescentes pelo abandono e pela experiência da institucionalização. Davi, por exemplo, relatou que na condição de educador, cobra e se empenha o máximo para que possam melhorar as condições desses adolescentes e assim superar as dificuldades, para que se tornem "cidadãos do bem". Já a educadora Milka afirmou que nenhum dos adolescentes estava preparado para lidar com o mundo fora do abrigo:

\begin{abstract}
Porque aqui dentro, eu acho assim, né? Porque aqui dentro não é igual lá fora. Lá fora as pessoas têm respeito ao outro, sim, mas eles têm os direitos, e aqui dentro eles têm mais direito do que dever. Então eles acham que eles podem tudo né? E sendo que lá fora se eles, quando eles cair lá fora, lá num pode tudo né? As pessoas vão reagir com ele da maneira que teria que ser mesmo. Porque eles são protegidos então a gente num tem como né, corrigir eles da maneira que teria que ser corrido, que corrigi um filho. E lá fora não, se eles forem fazer com a gente, com os outros o que eles fazem com a gente aqui, eles vão ter outra resposta. (Educadora Milka).
\end{abstract}

Talvez seja mesmo dificil pensar um futuro (para si mesmo ou para o outro) ou uma expectativa de futuro quando na verdade a pessoa se vê privada de suas raízes e se vê obrigada a conviver com estranhos. De acordo com Silva (1997), o processo de institucionalização consolida a estigmatização do indivíduo, que, para tentar se reerguer, precisa resolver o passado em busca de si mesmo e de sua família. Precisa tentar alterar fatos jurídicos, questionar os mais importantes aspectos de sua vida, corrigir as distorções cometidas contra sua própria individualidade para, enfim, ter uma identidade que possa ser considerada pelas pessoas como "normal". 


\section{Considerações finais}

Como resultado mais significativo da pesquisa, foram identificadas variadas formas de tensão vivenciadas pelos adolescentes nas situações de formação educativa simultâneas, na escola e no abrigo. Essas tensões eram produzidas mediante um conjunto de elementos das realidades vivenciada por eles, no abrigo e na escola, como situações de fuga física e simbólica, estigmas, isolamentos, problemas no aprendizado escolar, dificuldades de inclusão nas turmas e na escola, conformação e negação dos sujeitos.

Observou-se também que os adolescentes pesquisados não apresentavam muitas expectativas em relação à escola e que, portanto, a escola não tinha muito sentido para eles, ou que apresentava um sentido diferente daquele que é pregado pela sociedade, como algo que é necessariamente bom.

Contudo, apesar dessa negação do "valor" da escola, constatou-se uma tentativa de adequação à escola por parte dos adolescentes. Entre a negação da escola e a adesão a ela, estão às experiências desses adolescentes, que transitam em um complexo de sentidos e percepções, muitas vezes, contraditórios e sem uma unidade integradora, sobre si mesmos e sobre a condição social em que vivem. Essa ambígua relação de resistência e adesão parece configurar fortemente a lógica da experiência social e, consequentemente, a construção de si mesmo. Se as estratégias de fuga fazem parte dos esforços para a busca da liberdade para o corpo, os mecanismos de resistência significam os esforços para a preservação dos fatores que compõem a subjetividade dos adolescentes.

Outro resultado relevante refere-se à percepção dos educadores e dos professores sobre as responsabilidades das duas instituições (escolar e de acolhimento) em relação aos cuidados e educação dos adolescentes. Os relatos indicaram uma culpabilização recíproca: o professor responsabiliza o abrigo e o interpela para que resolva os problemas do adolescente, e o educador, por sua vez, responsabiliza a escola fazendo o mesmo movimento. Assim, a vida escolar do adolescente passa a se constituir sempre como "um Interfaces da Educ., Paranaíba, v.11, n.32, p. 432 - 465, 2020 
problema", como algo que deve ser resolvido pelo outro, permitindo aos profissionais das duas instituições um sentimento de conformação em relação a sua própria atuação diante dos adolescentes. Em ambos os casos, tanto a escola quanto o abrigo, responsabilizam também o sistema e, nesse jogo de hetero-responsabilização, mais uma vez o adolescente fica à mercê de um sistema social e político que (re)produz a desigualdade e a exclusão social.

De um modo geral, os resultados encontrados confirmam a hipótese inicial de que os processos de escolarização e os itinerários escolares de adolescentes institucionalizados sob tutela do Estado, além de uma clivagem imposta pela origem social e cultural, são influenciados pelas condições sociais e educacionais vivenciadas por eles em uma dupla e híbrida experiência social no acolhimento institucional e nas escolas.

Desse modo, ressaltamos que os resultados deste estudo, além de nos permitir conhecer e dar visibilidade a um público de crianças e adolesces geralmente invisibilizados no campo educacional, também contribui para ampliar o campo clássico dos estudos da Sociologia da Educação sobre as desigualdades sociais e escolares, ao colocar foco sobre condições sociais e modos de viver a escolarização pouco abordados nesse campo de estudo.

\section{REFERÊNCIAS}

BOURDIEU, Pierre. A economia das trocas simbólicas. São Paulo: Editora Perspectiva, 2007

BOURDIEU, Pierre. A distinção: critica social do julgamento. São Paulo: Edusp, Porto Alegre Zouk, 2008

BOURDIEU. Pierre. Os excluídos do interior. In CATANI, A. e NOGUEIRA, Maria Alice (Orgs.) . P. Bourdieu, Escritos de Educação. 14. ed. Petrópolis: Vozes, 2013

BRASIL. Conselho Nacional do Ministério Público. Relatório da Infância e Juventude. Relatório da Infância e Juventude - Resolução no 71/2011: Um olhar mais atento aos serviços de acolhimento de crianças e adolescentes no país. Brasília: Conselho Nacional do Ministério Público, 2013.108 p. il. 
BRASIL. Lei n.12.010, de 03 de agosto de 2009. Dispõe sobre adoção; altera as Leis nos 8.069, de 13 de julho de 1990 - Estatuto da Criança e do Adolescente, 8.560, de 29 de dezembro de 1992; revoga dispositivos da Lei no10.406, de 10 de janeiro de 2002 - Código Civil, e da Consolidação das Leis do Trabalho - CLT, aprovada pelo Decreto-Lei no 5.452, de $1^{\circ}$ de maio de 1943. Diário Oficial da União, Brasília, 04 de ago. de 2009.

CONSELHO NACIONAL DE JUSTIÇA. Sistema Nacional de Adoção e Acolhimento: visão integral sobre a infância. Ago. 2019. Disponivel em https://www.cnj.jus.br/sistema-nacional-de-adocao-e-acolhimento-visao-integralsobre-a-infancia/ Acesso em 03.02.2020.

CRUZ, Dalva Stella Pinheiro da. Entre o abrigo e a escola: o processo de escolarização dos adolescentes do Centro Social Renascer em Duque de Caxias. 2004. 136f. Dissertação (Mestrado) - Programa de Pós-Graduação em Educação, Universidade Federal do Rio de Janeiro, Rio de Janeiro, 2004.

DUBET, François. Sociologia da experiência. Coleção: Epistemologia e Sociedade. Editons du Seuil, 1994.

GOFFMAN, Erving. Estigma. Notas sobre a manipulação da identidade deteriorada. Tradução: Márcia Bandeira De Mello Leite Nunes. Revisão Técnica: Gilberto Velho. Editora Zahar Editores S.A., Quarta Edição, Rio de Janeiro, 1982.

GOFFMAN, Erving. Manicômios, prisões e conventos. Equipe de realização Tradução: Dante Moreira Leite; Revisão: Antenor Celestino de Souza; Produção: Lúcio Gomes Machado; Capa: Moysés Baumstein. Editora Perspectiva, 1974.

LÜDKE, Menga e ANDRÉ, Marli E. D. A. Pesquisa em educação: abordagens qualitativas. São Paulo: EPU, 1986.

RIZZINI, Irene. A institucionalização de crianças no Brasil: percurso histórico e desafios do presente/Irene Rizzini, Irma Rizzini. - Rio de Janeiro: Ed. PUC-Rio; São Paulo: Loyola, 2003.

SILVA, Roberto da. Os filhos do Governo. A formação da identidade criminosa em crianças órfãs e abandonadas. São Paulo/SP. Editora Ática, 1997.

TAVARES, Nelma. "Tia, você me adota?": o abrigo e a escola na constituição subjetiva da criança sob tutela do Estado.2014. 149 f. Dissertação (Mestrado) Programa de Pós-Graduação em Educação, Universidade Federal do Espírito Santo, Vitória, 2014. 


\section{ANEXO 1 - ROTEIRO DAS ENTREVISTAS SEMIESTRUTURADAS COM OS(AS) ADOLESCENTES}

\section{Antes do Abrigo}

1.1 Você se lembra quando veio morar no abrigo?

1.2 Antes de morar aqui, você morava com quem? Quem mais morava na casa? Quem ditava as regras nessa casa? Você se lembra o que podia fazer e o que não podia?

1.3 Você lembra qual idade entrou na escola? Lembra como foi isso? Se você gostou ou não gostou de entrar para a escola.

1.4 Quando aqui nessa instituição, você já frequentava a escola? Se sim, qual escola? Gostava da escola? Quem te ajudava nas tarefas escolares? Tem lembrança de algum de seus professores. O que você pensa sobre eles?

\section{Depois do Abrigo - Relacionamento com a escola}

2.1 Qual série você está hoje? Qual escola? Você sabe ler e escrever?

$2.2 \mathrm{O}$ que você pensa da escola? Gosta de estudar?

$2.3 \mathrm{O}$ que você mais gosta da escola? Atividades mais legais...

$2.4 \mathrm{O}$ que você menos gosta da escola? Atividades mais chatas...

$2.5 \mathrm{O}$ que você pensa de seus colegas de classe? E os da escola?

2.6 Quais são as matérias que você tem mais dificuldades? Por quê?

2.7 Quais são as matérias que você mais gosta? Por quê?

2.8 Como você vê seu professor(a)? Tem quantos professores?

2.9 O que aprende de certo e errado na escola? Quem dita as regras na escola?

2.10 Você brinca na escola? Quando? Com quem?

2.11. Onde você fica no recreio? Faz o que? Com quem?

2.12 Como é o seu comportamento na escola? Você acha que é um bom aluno? Por quê?

2.13 Você encontra alguma dificuldade na escola, com os colegas, com os professores? De que tipo? 
2.14 Quando você tem alguma dificuldade na escola, a quem você procura? Essa pessoa te ajuda? Como?

2.15. Você acha que a escola vai ajudar no seu futuro? Em quê?

\section{Relacionamento no Abrigo - Cotidiano}

3.1 Quem leva você para a escola? Quem decide em qual escola vai estudar? Você faz dever, alguém te ajuda? Como que faz, tem horário? E quando tem trabalho escolar...

3.2 Você faz atividades extra escolares? Onde? Como?

3.3 Quem faz dever, trabalhos da escola com você?

3.4. Com quem você passa mais tempo. Quem cuida de você no abrigo?

3.5 As pessoas do abrigo escutam você, consideram a sua opinião, o que você gosta? O que você quer fazer?

3.6 Você ajuda nas tarefas domésticas do abrigo? O que você costuma fazer?

3.7 Quem leva você ao médico? Ao dentista?

$3.8 \mathrm{O}$ que faz para se divertir? Costuma brincar que tipo de brincadeira? Com quem?

3.9 Quem dita às regras no abrigo? Como você vê as regras...

$3.10 \mathrm{O}$ que você gosta no abrigo? O que você não gosta no abrigo? Sente falta de alguma coisa, de quê?

3.11 Conte-me um dia seu... Desde a hora em que você acorda até a hora de dormir.

\section{Criança/Adolescente}

4.1 Você sabe por que está no abrigo? O que você pensa sobre isso?

4.2 Como você vê o abrigo? Acha o abrigo legal? O que é bom e o que é ruim em ficar no abrigo?

4.3 Você encontra alguma dificuldade no abrigo? De que tipo? Como você faz para superar essas dificuldades? Alguma pessoa te dá apoio, ou te ajuda? Como?

4.4 Você pensa em estudar até quando, até qual idade? Tem ideia de alguma profissão a seguir? Quer trabalhar com o que quando for adulto?

Interfaces da Educ., Paranaíba, v.11, n.32, p. 432 - 465, 2020 
4.5 Acha que a escola é importante para você? Por quê?

4.6 Se pudesse escolher onde e com quem morar, onde estaria agora neste momento? O que você estaria fazendo agora?

4.7 Como você se imagina no futuro... quando sair do abrigo, quando estiver $\operatorname{rapaz...}$

\section{ANEXO 2 - QUESTIONÁRIO SÓCIO-ECONÔMICO \\ (Preenchimento por um técnico da unidade pesquisada)}

\section{Criança/adolescente}

acolhido(a):

1. Dados gerais:

Quanto tempo a criança/adolescente está no abrigo?

Recebe visita de alguém? Quem?

Em qual série está na escola?

2. Quais motivos levaram essa criança/adolescente a ser institucionalizada?

() Abandono

() Violência Doméstica

() Violência Sexual

() Problemas com álcool e drogas do responsável

() Outro

3. Essa criança/adolescente tem em seu registro de nascimento, nome da mãe:

() Sim () Não 
4. Qual ocupação/Profissão da mãe?

5. Essa criança/adolescente tem em seu registro de nascimento, nome do pai:

(_) Sim () Não

6. Qual ocupação/Profissão do pai?

7. O pai e a mãe dessa criança/adolescente mantêm relacionamento conjugal atualmente:

() Sim () Não

8. Sabe se a criança/adolescente acolhida/o tem irmãos? Quantos?

9. Sabe a posição dele na fratria?

10. Ele(a) tem irmãos no abrigo?

Quantos?

11. Qual o estado civil da mãe?

() Solteiro(a).

() Casado(a).

() Separado(a) judicialmente/divorciado(a).

() Viúvo(a).

() Outro.

12. Qual o estado civil do pai?

() Solteiro(a).

() Casado(a).

() Separado(a) judicialmente/divorciado(a).

() Viúvo(a).

() Outro. 
13. Até que etapa de escolarização concluiu o pai dessa criança/adolescente?

() Nenhuma (analfabeto)

() Ensino Fundamental: $1^{\circ}$ ao $5^{\circ}$ ano $\left(1^{\mathrm{a}}\right.$ a $4^{\mathrm{a}}$ série) completo

() Ensino Fundamental: $1^{\circ}$ ao $5^{\circ}$ ano $\left(1^{\mathrm{a}}\right.$ a $4^{\mathrm{a}}$ série) incompleto

() Ensino Fundamental: $6^{\circ}$ ao $9^{\circ}$ ano $\left(5^{\mathrm{a}}\right.$ a $8^{\mathrm{a}}$ série) completo.

() Ensino Fundamental: $6^{\circ}$ ao $9^{\circ}$ ano $\left(5^{\mathrm{a}}\right.$ a $8^{\mathrm{a}}$ série) incompleto.

() Ensino Médio completo.

() Ensino Médio incompleto.

() Ensino Superior (graduação) completo

() Ensino superior incompleto

() Não tenho a informação.

14. Até que etapa de escolarização concluiu a mãe dessa criança/adolescente?

() Nenhuma (analfabeto)

() Ensino Fundamental: $1^{\circ}$ ao $5^{\circ}$ ano $\left(1^{\mathrm{a}}\right.$ a $4^{\mathrm{a}}$ série) completo

() Ensino Fundamental: $1^{\circ}$ ao $5^{\circ}$ ano $\left(1^{\mathrm{a}}\right.$ a $4^{\mathrm{a}}$ série) incompleto

() Ensino Fundamental: $6^{\circ}$ ao $9^{\circ}$ ano $\left(5^{\mathrm{a}}\right.$ a $8^{\mathrm{a}}$ série $)$ completo.

() Ensino Fundamental: $6^{\circ}$ ao $9^{\circ}$ ano $\left(5^{\mathrm{a}}\right.$ a $8^{\mathrm{a}}$ série) incompleto.

() Ensino Médio completo.

() Ensino Médio incompleto.

() Ensino Superior (graduação) completo

() Ensino superior incompleto

() Não tenho a informação.

15. Com quem essa criança/adolescente morava antes de ser institucionalizada?

() Pai

() Mãe

() Avós

() Outro(s) 
16. Qual a renda total da família, dessa criança, considerando com quem morava antes do abrigo?

() Até 1,5 salário mínimo (até $\mathrm{R} \$ 1.320,00$ ).

() De 1,5 a 3 salários mínimos ( $R \$ 1.320,01$ a $R \$ 2.640,00)$.

() De 3 a 4,5 salários mínimos ( $R$ \$2.640,01 a $R \$ 3.960,00)$.

() De 4,5 a 6 salários mínimos ( $R \$ 3.960,01$ a $R \$ 5.280,00)$.

() De 6 a 10 salários mínimos ( $\mathrm{R} \$ 5.280,01$ a $\mathrm{R} \$ 8.800,00)$.

() De 10 a 30 salários mínimos ( $\mathrm{R} \$ 8.800,01$ a $\mathrm{R} \$ 26.400,00)$.

() Acima de 30 salários mínimos (mais de $\mathrm{R} \$ 26.400,00$ ).

() Não tem renda e os gastos são financiados por ajuda de familiares ou outras pessoas.

() Não tem renda e seus gastos são financiados por programas governamentais e ajuda da assistência social.

() Não sabe informar.

17. A família, com quem morava antes do abrigo, possuía residência própria?

() Sim - Quitada

() Sim - Financiada

() Não - Alugada

() Não - Cedida

() Outro

18. Em relação à família, com quem morava antes do abrigo, quantas pessoas residiam na mesma casa?

() Uma.

() Duas.

() Três.

() Quatro.

() Cinco ou mais. 
19. Outras observações ou informações: 